\title{
Promoting trust in police: Findings from a randomized experimental field trial of procedural justice policing
}

\author{
Kristina Murphy \\ School of Criminology and Criminal Justice \\ Griffith University \\ Lorraine Mazerolle \\ ARC Center of Excellence in Policing and Security \\ The University of Queensland \\ $\&$ \\ Sarah Bennett \\ ARC Center of Excellence in Policing and Security \\ The University of Queensland
}

Corresponding Author:

Associate Professor Kristina Murphy

School of Criminology and Criminal Justice

Griffith University

Building M10, Messines Ridge Rd, Mt Gravatt

Queensland, 4122, Australia

Email: t.murphy@griffith.edu.au

Submitted to Policing and Society - Manuscript GPAS-2012-0110

Date of acceptance: 22 March 2013

Running Head: Procedural justice policing in practice 


\title{
Author acknowledgements
}

The research reported in this paper was funded, in its entirety, by the Australian Research Council (ARC) Centre of Excellence in Policing and Security (CEPS). The authors thank the team of researchers from the University of Queensland (Institute for Social Science Research) and Griffith University who participated in a variety of ways to bring this trial to fruition. The partnership between the research team and the Queensland Police Service is particularly acknowledged. The views expressed in this paper are those of the authors and are not those of the Queensland Police Service. Responsibility for any errors of omission or commission remains with the authors. The Queensland Police Service expressly disclaims any liability for any damage resulting from the use of the material contained in this publication and will not be responsible for any loss, howsoever arising, from use or reliance on this material.

\begin{abstract}
This paper reports findings from the world's first randomized experimental field trial of procedural justice policing. We tested whether or not procedural justice could be used by police agencies during short, routine traffic stops to increase public trust and confidence in police. Using survey data from 2,762 Australian drivers who had been exposed to either a procedural justice script (experimental condition) or a standard police procedure (control condition), it was found that trust and confidence in police was higher in the experimental condition. This was even the case after respondents' demographic background and general perceptions of police were taken into account. Similar effects were not found for drivers' obligation to obey police, nor their willingness to cooperate with police. Importantly, however, trust in police did predict both obligation to obey police and the willingness to cooperate with police. The findings have important implications for procedural justice research and policing practice.
\end{abstract}

\section{Keywords: procedural justice; trust; policing; experimental design}




\section{Introduction}

Over the past few decades, police agencies in Australia, the United Kingdom and the United States have made important steps forward in terms of the quality of policing they provide the community (Tyler and Murphy 2011). Police officers are now being recruited with higher levels of education, they receive more training prior to and after becoming sworn police officers, the gender and ethnic profile of new recruits is more diverse than ever before, and police now have greater resources available to them in which to tackle crime. Outreach to historically disenfranchised groups in the community and a commitment to engagement with the community has also become an important focus for police in recent years (Cherney and Chui 2009; Hough et al. 2010; Skogan and Frydl 2004). A review of policing by Skogan and Frydl (2004), for example, detailed evidence of greater police professionalism and more sophisticated policing practices.

Despite increases in the overall quality of policing, support for police - often measured as trust and confidence in the police - has not enjoyed similar rates of improvement. The percentage of Americans expressing confidence in the police between 1980 and 2010, for example, has generally ranged between 50 and 60 per cent, and has changed little over the 30-year period (Gallup 2010). In Australia, overall trust and confidence in police is higher than in the US, yet trust and confidence in police has actually fallen slightly over the same 30 year period. In 1983, for example, 80 per cent of Australians expressed confidence in police, compared to 76 per cent in 1995, 68 per cent in 2001 and 72 per cent in 2003 (Bean 2004). Similarly, Bradford, Jackson and Stanko (2009) report that public confidence in police in England and Wales has similarly declined since the 1960’s.

This discrepancy between improvement of police professionalism and declining levels of public trust and confidence in police suggests that police across these three countries are not capturing the full benefits of heightened professionalism and improved performance. Tyler and Murphy (2011: 1) propose that some of these potential, unrealised benefits might include: greater public deference to police during face-to-face encounters; higher levels of voluntary cooperation with police; and greater compliance with the law. Thus, recognising that trust and confidence in police is important for shaping cooperative behaviours with police and examining exactly how trust and confidence in police might be produced and sustained is important for advancing police policy and practice in the future. 
Our paper presents results from the world's first experimental field trial to carefully operationalise the key principles of procedural justice in a short, replicable script. We argue here that a procedural justice-based policing approach offers an effective way to build trust and confidence in police. We begin our paper with a discussion about 'trust' and canvass research from the procedural justice field. We then briefly describe the Queensland Community Engagement Trial (QCET), a randomized experimental field trial in which an Australian police agency utilised procedural justice principles in encounters with the public. This is followed by the presentation of our empirical findings. We demonstrate a direct link between police use of procedural justice and trust and confidence in police. We conclude with a discussion of the implications of our study for policing practice.

\section{Trust: instrumental- versus interpersonal-based trust}

Whilst 'trust' is an abstract concept, it is a concept that is firmly rooted in experience. Individuals' interactions with other people and the past experiences they have had with institutions create expectations about how they will be treated in the future (Goldsmith 2005). If they have been treated poorly, then expectations for future interactions are likely to be negative in nature and can lead to distrust in the individual or institution they come in contact with. In defining trust, Hardin (2006: 17) recently stated: "to say we trust you means we believe you have the right intentions toward us and that you are competent to do what we trust you to do". Here, Hardin highlights both the interpersonal and instrumental aspects of trust.

The distinction between instrumental and interpersonal trust is important (Murphy 2004). Instrumental-based trust sees trust as being linked to competence and individual beliefs about the likelihood of receiving positive outcomes from interactions with authorities. In the policing context, for example, instrumental-based trust might be linked to judgements about public safety. The argument underlying this perspective suggests that citizens will undertake some immediate costly effort such as complying with the law under the assumption that they will receive some future collective benefit such as a reduction in crime rates and increased public safety. The positive experience of receiving these benefits goes on to enhance trust and confidence in police and hence the likelihood of further compliance with the law. Such a view therefore suggests that if police perform their job well, solve local problems, and deal with crime effectively, then this will lead to greater levels of public trust and confidence in the institution of policing. In contrast, the negative experience of not receiving those benefits 
from police would lead to a reduction in both trust and confidence in police, and compliance with the law.

However, as noted recently by Jackson and Bradford (2009) trust extends beyond narrow public assessments that police perform their duties effectively and efficiently to include a sense that the police understand the needs of the community, and that they treat people fairly. Interpersonal or social-based trust, therefore, is trust that is based on social relationships and fair treatment. If citizens believe that the police are trying to be fair, that they treat individuals with dignity and respect, and that they express genuine concern for the members of the public, then they will trust the motives of that authority and will develop a long-term commitment to accepting its decisions and will be more likely to comply with its rules (Tyler and Huo 2002).

It appears then that how police perform, and how their acts are experienced by citizens, are both important for building trust and confidence. While not downplaying the role of police performance in shaping trust and confidence in police, it has been suggested that interpersonal experiences may in fact be more crucial for determining a person's trust and confidence in authority. Several researchers (e.g. Folger and Konovsky 1989; Levi 1998; Tyler and Huo 2002) have suggested that the key to creating trust is to act in ways that citizens will experience as fair. This is the core argument made in the procedural justice literature (see Tyler and Huo 2002).

\section{Procedural justice and trust}

Procedural justice concerns the perceived fairness of the procedures involved in decisionmaking and the perceived treatment one receives from a decision-maker (i.e. an authority). Procedural justice is commonly defined in terms of four issues: voice; neutrality; respect; and trustworthiness (Tyler and Murphy 2011). The first two are concerned with how decisions are made and involve voice; the second two involve the fairness in which people are treated by authorities. People value the chance to explain their situation, or tell their side of the story, during encounters with institutions of authority. Being provided with 'voice' (see Tyler and Murphy 2011) leaves people feeling more satisfied with an encounter because they feel that those in the position of authority have been presented with all the facts before a decision has been made. People also react positively to evidence that the authority with whom they are dealing with is neutral. Neutrality involves making decisions based upon the facts of the 
case, not on an officer's personal opinion or biases (see Tyler 1990). It also involves ensuring consistent and equal treatment across groups. People are particularly sensitive to signs that authorities treat them with dignity and respect (see Tyler 1990). People believe they have a right to polite and respectful treatment and react very negatively to signs of rudeness and demeaning interpersonal treatment. Finally, people look for cues that provide information about the intentions and character of the legal authorities with whom they are dealing (i.e. their trustworthiness). People react very favourably when they feel authorities are benevolent and caring, and are sincerely trying to do what is best for the people they are dealing with (Tyler and Murphy 2011).

A large body of research exists that demonstrates the important impact that procedural justice has on people's attitudes and behaviours (e.g. Hinds and Murphy 2007; Murphy, Hinds and Fleming 2008; Sunshine and Tyler 2003; Tyler 1990). Across a range of different contexts, including policing, we know that procedural justice can have a specific and positive influence on people's trust and confidence in authorities. For example, Tyler and Huo (2002) found that procedural justice promotes trust in police. In their study of 1,656 Californians who had had personal encounters with police, procedural justice was a key predictor of public trust in police, more so than other instrumental factors. Tyler (1990) also demonstrates, using survey data collected from 1,575 residents of Chicago, that the quality of treatment residents received from police was the primary factor shaping their trust and confidence in police.

Procedural justice research also shows a link between trust in authority and subsequent cooperative behaviour. Tyler (2005) used survey data from 1,653 New Yorkers from various ethnic backgrounds (Whites, African Americans and Hispanics) to show that trust and confidence in police was a major predictor of the publics' willingness to cooperate with police in crime fighting efforts, across all ethnic groups studied. If people trusted police they were more likely to cooperate with them (see also DeCremer and Tyler 2007; for similar findings in other regulatory settings see Kim and Mauborgne 1993; Murphy 2004; Scholz and Lubell 1998; Tyler and Degoey 1996).

These findings are important because the extent to which people have trust in police appears to suggest that it will impact on their propensity to cooperate with, and defer to, police officers across a whole range of policing activities. Understanding motivations for deference 
to police is critical because, as Tyler (2004) suggests, unless the police are widely obeyed by the public, the capacity of police to maintain order is compromised.

\section{Limitations of procedural justice research to date}

Scholars throughout the world show that procedural justice is widely effective for improving trust and confidence in police, and shaping deference to police authority (see Hohl, Bradford and Stanko 2010; Mazerolle et al. 2010; McCluskey 2003). Nonetheless, a significant limitation of existing research to date is the lack of field assessment as to whether or not (and how) procedural justice actually works in practice. While the extant literature contains a considerable amount of survey and observational research into procedurally just approaches in policing, no studies to date have used randomized experimental field designs that attempt to ascertain the relevance of procedural justice theory to policing practice. This was highlighted recently by Weisburd, Mastrofski and Telep (2009; cited in Mazerolle et al. 2010: 1), who stated: “[e]xisting studies provide important insights into our understanding of legitimacy and procedural justice in policing, but there has not been an experimental field study testing key propositions set forth by proponents of legitimacy policing.”

The problem with the existing procedural justice research is that the conclusions are generally drawn using correlational data. While it is clear from these data that perceptions of procedural justice are related to feelings of trust and confidence, we cannot be 100 per cent certain that receiving procedural justice actually causes changes in the level of trust and confidence in police. A couple of quasi-experiments have recently been conducted, and the findings from these studies suggest that procedural justice does have a significant positive impact on trust and confidence in police (see Hohl et al. 2010; Jonathan-Zamir and Weisburd, in press). We also know that at least two recent experiments of procedural justice have been conducted in police academies testing the efficacy of procedural justice training of police officers (see Rosenbaum and Lawrence 2012; Schuck and Rosenbaum 2011; Wheller, Mills and Quinton, 2012). However, no study uses a true randomized experimental field trial to test whether or not (and how) procedural justice-based policing actually works in real-world field encounters with the public.

It is important to better understand the operational components and effects of procedural justice policing given the current interest by police agencies to adopt procedural justice into policing practice. For example, in the United Kingdom, the National Policing Improvement 
Agency (NPIA) recently fielded core questions about procedural justice, public trust in police, and public perceptions of police legitimacy in population surveys in England and Wales (Hough et al. 2010). They aim to use the findings to inform policing strategies in the United Kingdom. The NPIA also funded a systematic review of research undertaken in the procedural justice and police legitimacy field (Mazerolle et al. 2010) and they have trialled training police recruits in the use of procedural justice (Wheller et al. 2012). In the US, the Department of Justice also recently funded a project by the Chicago Police Department and the University of Illinois to train new police recruits in the use of procedural justice (Rosenbaum and Lawrence 2012; Schuck and Rosenbaum 2011). Similarly in 2009 in Australia, Police Ministers around the country agreed to develop a principles-based model of best practice for policing crime and anti-social behaviour by young people. This model - The National Youth Policing Model - is guided by nine evidence-based principles (Commonwealth of Australia 2010), including trust and respect, which recognise research evidence from the procedural justice field.

Hence, to address the major gap and resulting limitation of procedural justice research to date, this study presents data collected from the world's first randomized experimental field trial of procedural-justice based policing: The Queensland Community Engagement Trial (QCET). The following sections describe the trial and the study methodology.

\section{The Queensland Community Engagement Trial}

In partnership with researchers from the University of Queensland in Brisbane, Australia, the Queensland Police Service (QPS) implemented a change in police procedure during 60 major Random Breath Test (RBT) operations, involving 21,000 drivers. ${ }^{1}$ The Queensland Community Engagement Trial (QCET) used a randomized experimental field trial design to examine whether introducing elements of procedural justice into the random breath testing encounters (experimental condition) could increase public perceptions of procedural justice and police legitimacy relative to the standard police procedure (control condition). Because an experimental manipulation was used in the trial, the causal relationship between the treatment drivers received from police during the encounter and the subsequent impact it had on their trust and confidence in police can be assessed. Drivers who were involved in the field trial were asked to complete a self-report survey of their experience and return it in their own time to the University of Queensland (for more details about the QCET methodology see Mazerolle, Bennett, Antrobus \& Eggins, 2012). 
A police stop for the purposes of random breath testing for alcohol is the most common reason people in Australia have contact with police. Fifty seven per cent of all police contacts with Australian citizens in any given year are for a random breath test (Roberts and Indermaur 2009). A recent Australian study showed that perceptions of procedural justice are particularly important to people who have had a police-initiated contact such as a police stop (Murphy 2009), and Bradford et al. (2009) also found correlational evidence suggesting positive encounters with police in the United Kingdom could shape trust and confidence in police. Such findings indicate that police may be able to effectively build trust with a large number of people in the community through using procedural justice during random breath testing encounters.

\section{Previous findings from QCET}

In a paper that presents the main findings of the QCET study, Mazerolle et al (2012) demonstrated that the QCET manipulation resulted in a number of positive outcomes. Drivers exposed to the experimental condition (i.e., those who received the new procedural justice elements) were more likely than drivers in the control condition to perceive police treatment to be procedurally fair. Mazerolle et al (2012) also showed that relative to the control condition, the experimental manipulation was more likely to change drivers' views about drink driving and their views about police. Finally, they found that both satisfaction and compliance with the police officer conducting the RBT was significantly higher in the experimental condition than in the control condition.

A second published paper detailing results from the study (Mazerolle, Antrobus, Bennett \& Tyler, 2013) shows that the procedural justice condition not only produced more favourable perceptions of the specific encounter with police than the control condition, but that these positive encounters also shaped people's views more generally of police. In this paper (Mazerolle et al, 2013), the authors found that those who believed the RBT encounter was more procedurally fair were in turn more likely to rate police in general to be procedurally fair. General perceptions of procedural fairness were also related to greater satisfaction with police and higher perceptions of police legitimacy. Those who saw police as more legitimate were in turn more likely to report that they would cooperate with police (see Mazerolle et al, 2013). 


\section{The Present Study}

The present study builds upon the two papers cited above in five ways. First, in this paper, we specifically seek to examine whether or not the QCET manipulation had a direct positive impact on improving the public's trust and confidence in the police, and whether the manipulation continued to have an effect even after citizens' general perceptions about police conduct and police performance are taken into account. Neither of the two papers mentioned above assessed whether or not the trial had a positive effect on trust and confidence in police.

Second, in this present paper, we consider the impact of people's general attitudes to police on trust and confidence in police. Brandl et al. (1994), for example, found that the effect of personal experience on attitudes to police is extremely small. They suggest that people's general views of the police matter most when interpreting experiences. In other words, general attitudes shape how people interpret their experiences, not the type of treatment they receive during an encounter. It is important to ascertain whether the experimental manipulation of procedural justice in QCET can still predict effects on trust and confidence in police when people's general views about police use of procedural justice are taken into account. Mazerolle et al (2012) examined general perceptions of procedural justice in their statistical model. However, they did not assess the direct effect of the experimental manipulation on trust and confidence when taking into account general perceptions of procedural justice.

Third, Mazerolle et al (2013) did not include general attitudes about police effectiveness in dealing with crime in the community (i.e., an instrumental variable). The present study assesses the direct impact of the experimental manipulation on trust and confidence in police while controlling for general perceptions of police (both general perceptions of procedural justice and police effectiveness).

Fourth, in this paper we control for the demographic characteristics of the study participants to assess the way that age, gender and race shapes perceptions of trust and confidence in police. Neither of the two previous QCET papers included demographic variables as control variables when predicting differences across the experimental and control groups. The addition of demographic background factors in the present study is particularly important given past research has consistently shown that certain groups of people view police more 
favourably. In a review of literature, Skogan (2006) identified a number of demographic background variables that have been shown to consistently have an impact on evaluations of police. These variables include race, age and socio-economic status. For example, a substantial body of United States-based research has examined racial differences in the evaluations people make of police. It is consistently revealed that racial minorities provide less favourable assessments of police than non-minority groups (Gallagher et al. 2001; Sampson and Jeglum-Bartusch 1998; Tyler and Huo 2002). In Australia, Chan (1997) has also demonstrated that ethnic minority groups are more critical of police than majority group members (see also Murphy and Cherney 2011). Age is another factor that has been found to be a strong predictor of attitudes to police. Younger people are more likely to be stopped by police, are more likely to have contact with police, are more likely to be arrested, and are more likely to be victims of violent crime than their older counterparts. Research has found that this can result in lower evaluations of police (Skogan and Steiner 2004). Further, it has been found that those with a greater stake in society (i.e., those from higher socio-economic groups) are more inclined to support police. It has been shown that middle- and upper-class citizens are more likely to rate police positively after encounters (Correia 2000). Skogan (2006) notes that this may be due to the fact that police may be more deferential to these groups. The present study aims to evaluate whether in experimental conditions these demographic background factors matter in predicting trust and confidence in police. If the present study finds that the experimental manipulation has a significant effect on trust and confidence levels while demographic factors do not, then it will suggest that background factors matter less than the actual treatment one receives from police during an encounter.

Finally, the present study also tests how important trust in police might be for shaping citizen's subsequent self-reported obligation to obey police and their willingness to cooperate with police. In this paper, we specifically assess how trust conditions people's obligation to obey authority and how it shapes willingness to cooperate with police. Past research has shown trust to be an important predictor of people's willingness to cooperate with authorities (see Murphy 2004). We aim to assess whether this is also the case in an experimental context. As noted earlier, the QCET trial was the first of its kind in the world. It therefore represents the most robust test anywhere in the world of the practical nature of procedural justice-based policing.

\section{Method}




\section{Participants and Procedure}

Sixty scheduled RBT operations conducted between December 2009 and June 2010 were randomly assigned to either the control $(n=30)$ or experimental $(n=30)$ condition (see Mazerolle et al 2012 for details). Police in the experimental condition were provided with a scripted procedural justice protocol. This protocol was about seven times as long as the standard control protocol used by Queensland Police. In the procedural justice protocol officers were provided a script and were trained to focus on four procedural justice elements: voice, neutrality, trustworthiness, and respect. This contrasted sharply with the control condition where officers were simply instructed to ask drivers for a specimen of their breath for alcohol content analysis (i.e. business as usual).

To provide 'voice' in the experimental condition, police gave the stopped driver a newsletter that highlighted recent crime issues in the local area. Drivers were asked if they had any questions or if they had any suggestions for police priorities in their area. To display 'neutrality', the police officer explained the process that was being undertaken in the RBT and that the driver had not been singled out, but rather they had been randomly pulled over for a breath test. It was also explained that RBT's were conducted to reduce alcohol-related road accidents. To build 'trustworthiness', the police officer expressed their concerns about drink driving for the community, and indicated that they disliked having to tell family members that their loved ones had been injured or killed in a road accident. The number of alcohol related deaths in Queensland in the past year was mentioned to the driver and the police officer asked them to help police to reduce accidents by driving carefully. The officer ended the breath-testing encounter on a 'respectful' note with a gesture of courtesy to the driver (e.g. complementing them on the maintenance of their car; for wearing a seatbelt etcetera).

After a driver provided a specimen of their breath, the officer then invited them to complete a short survey of their experiences of the encounter and to return it to the University of Queensland in a reply-paid envelope, in their own time (drivers in both the control and experimental conditions received a survey). Across the 60 RBT operations approximately 21,000 drivers were involved in the study (8,985 in the experimental condition and 12,000 in the control condition). Survey responses were received from 1,107 drivers exposed to the experimental condition and 1,655 drivers from the control condition, representing an overall response rate of 13.16 per cent. A slightly higher proportion of drivers returned a survey in 
the control condition (13.79 per cent) compared to the experimental condition (12.32 per cent). Fifty per cent of respondents were female and the age of respondents ranged from 17 to $90(\mathrm{M}=47.19, \mathrm{SD}=14.71)$. The response rate for the survey is clearly low and could be due to the fact that no incentives were offered or no reminders to participate could be used. Other recent surveys undertaken in Australia suggest that after an initial mailing of a survey, usually only 20 percent of respondents will complete a survey with no further follow-up (see Murphy \& Byng, 2002; Murphy, Murphy \& Mearns, 2010). Fortunately there were no significant differences in the demographic makeup of respondents between the control and experimental conditions (see Mazerolle et al 2012). Hence, the relatively low response rate allows analysis given the randomized nature of the experimental design and the lack of demographic differences between the two groups. It should be noted, however, than nonrespondents may have differed substantially from respondents. There is no way of ascertaining whether this is the case, but readers are advised to take this into consideration when interpreting the findings.

\section{Measures}

The survey that police distributed to drivers after the RBT encounter contained a total of 126 questions (the same survey was used across both the experimental and control conditions). Some of the survey items relating to procedural justice were based on the work of Murphy et al (2010). For the purpose of the present study only survey measures relevant to the following categories of variables were utilised: (a) perceptions of procedural justice during the RBT encounter (called specific procedural justice); (b) general perceptions of police use of procedural justice with members of the public (called general procedural justice); (c) police performance/effectiveness; (d) trust and confidence; (e) obligation to obey police; (f) willingness to cooperate with police; and (g) demographic control variables (see Appendix for exact wording for all the questions used in the present study). Each scale was derived by summing scores across items for each respondent and dividing this score by the number of items used in the scale.

Experimental manipulation. The nature of the QCET study ensured that drivers received either the control protocol, or the procedural justice protocol, not both (see Mazerolle et al 2012). The condition that a survey respondent had been exposed to was recorded on the survey booklet they returned to the University of Queensland. For the purposes of the present 
study, the 'manipulation condition' measure was coded as $0=$ control and $1=$ experimental $(\mathrm{N}=$ 1,655 and 1,107 respectively).

Specific procedural justice. A specific procedural justice scale was constructed to determine whether drivers in the experimental condition, relative to drivers in the control condition, were significantly more likely to perceive their RBT encounter to be procedurally fair. Hence, this item was used simply as a manipulation check in this paper. The five items used to assess specific views of procedural justice were designed to assess whether respondents felt the police officer they had dealt with during the RBT was neutral and trustworthy, whether they provided them with voice, and whether police treated them with dignity and respect (e.g. "The police officer treated me with dignity and respect') measured on a five-point Likert scale from 1=strongly disagree to $5=$ strongly agree. A higher score on this scale reflects higher levels of perceived procedural justice (Cronbach's $\alpha=$ 0.88). Results of a separate confirmatory factor analysis revealed that all five items loaded onto a single factor.

General procedural justice. In addition to the items assessing specific perceptions of procedural justice during the RBT encounter, drivers were also asked about their general perceptions of police officers in Queensland. Specifically, they were asked to indicate whether they believed the police in general treat members of the public with procedural justice. Five items were used to construct the general procedural justice scale (e.g. "Police are always polite when dealing with people”. Perceptions of general procedural justice were again measured on a five-point Likert scale. Response categories ranged from 1=strongly disagree to $5=$ strongly agree (Cronbach's $\alpha=0.91$ ). Higher scores on this scale denote greater perceptions that the police use procedural justice when dealing with citizens.

Police effectiveness. Procedural justice literature shows that procedural justice usually matters more to people than instrumental factors when formulating views about authorities (Tyler 1990, 2006). However, as noted earlier, trust in police is also shaped by instrumental factors. Instrumental factors can include perceptions on how effectively police deal with crime in the community. Hence, a four-item 'effectiveness' scale was constructed to assess the importance of such factors for promoting trust in police (e.g. "How good a job do you think the police are doing in your neighbourhood at solving crime”). Items were measured on 
a Likert scale from $1=$ very poor job to $5=$ very good job (Cronbach's $\alpha=0.93$ ). Higher scores indicate respondents felt the police are more effective.

Trust and confidence. Trust and confidence in the police officer conducting the RBT was assessed via four items (e.g. "I felt that the police officer was trustworthy"). These were measured on a Likert scale from $1=$ strongly disagree to $5=$ strongly agree (Cronbach's $\alpha=$ 0.91). Higher scores on this measure represent greater levels of trust and confidence in police.

Obligation to obey police. Feelings of obligation to obey police provide a litmus test for examining whether police have authority over citizens. If people feel a strong obligation to obey police, survey research has shown that they will be more likely to comply with police directives, will be more likely to comply with the law in their everyday lives, and will be more willing to voluntarily cooperate with police in collaborative crime control efforts (Sunshine and Tyler 2003). Drivers in the QCET study were asked to indicate how obligated they felt to obey police. Obligation to obey was assessed via three items (eg. "I feel a moral obligation to obey police"), which were measured on a Likert scale from 1=strongly disagree to $5=$ strongly agree (Cronbach's $\alpha=0.85$ ). Higher scores suggest that respondents have greater feelings of obligation to obey.

Cooperation. Police rely on citizens to help them combat crime in the community. This involves asking citizens to assist police by reporting crimes, identifying suspects, and reporting suspicious behaviour. Respondents' self-reported willingness to voluntarily cooperate with police in this manner was assessed via a four-item scale (e.g. "How likely would you be to call police to report a crime"). Response categories ranged from 1=very unlikely to 5=very likely (Cronbach's $\alpha=0.57$ ), with higher scores denoting a greater willingness to cooperate with police.

Control variables. Finally, four demographic control variables were also included in the analyses. These were the respondents' gender $(0=$ male, $1=$ female), age (measured on a continuous variable), education level (1=postgraduate degree to $6=$ primary school) ${ }^{2}$, and whether respondents spoke a language other than English at home ( $0=$ English only, 1=language other than English). The education and language variables were used as proxies for socio-economic status and ethnic minority status, respectively. 


\section{Factor Analysis}

A principal components factor analysis with oblimin rotation was undertaken to test for the dimensionality of key variables used in this study (general procedural justice; police effectiveness; trust; obligation to obey police; willingness to cooperate with police). The scree plots and eigenvalues $(8.65,1.78,1.73,1.37,1.20,0.86,0.66)$ for this analysis suggested that five clear factors should be extracted. Inspection of the rotated pattern matrix (see Table 1) shows that the five factors extracted in the analysis support the scales that are described in the measures section, with all five scales explaining 74 per cent of the variation in the model. Factor 1 comprised five items measuring general procedural justice judgments; Factor 2 included four items measuring police effectiveness; Factor 3 comprised four items for cooperation; Factor 4 comprised four items assessing trust and confidence in police; and Factor 5 comprised three items that assessed obligation to obey police.

[insert Table 1 about here]

\section{Results}

\section{Descriptive Statistics}

Table 2 presents the means and standard deviations for the measures used in this study for participants in both the experimental and control conditions, respectively. There were significant differences between the two groups on three key measures. Independent samples t-tests revealed that when compared to control condition respondents, citizens in the experimental condition were significantly more likely to feel they were treated with procedural justice during the RBT encounter. Hence, this manipulation check confirms that the experimental protocol was perceived to be more procedurally fair (see also Mazerolle et al 2012). Drivers in the experimental condition were also significantly more likely to express that police in general treat people with procedural justice, and they were significantly more likely to have higher levels of trust and confidence in the police conducting the RBT. There were no differences between the groups on their views of police effectiveness, their obligation to obey police, or their willingness to cooperate with police.

[insert Table 2 about here] 


\section{Regression Analyses}

The main aim of our current paper is to ascertain whether or not introducing elements of procedural justice into policing practice could directly shape public trust and confidence in police, even after general perceptions of police and demographic background factors are taken into account. In order to address this aim, a regression analysis was undertaken to predict levels of trust, in which the experimental manipulation variable was entered into the regression model $(0=$ control and $1=$ experimental $)$ in conjunction with a set of attitudinal and demographic control variables.

It can be seen from Table 3 that a number of variables predicted trust in police. First, the experimental manipulation variable was positively related to trust and confidence, suggesting that citizens who received the experimental condition were significantly more likely to trust the police officer undertaking the RBT. Gender also had an effect on trust and confidence in police, so too did the police effectiveness and general procedural justice measures. These findings indicate that women were more likely than men to trust police. Further, those who felt the police were more effective in dealing with crime were more likely to have trust and confidence in police. Similarly, those who were more likely to feel that police generally use procedural justice when dealing with the public were also more likely to trust police.

It can also be seen from Table 3 that drivers' general perceptions of an encounter are stronger predictors of trust and confidence in police than other variables in the model. Specifically, the general procedural justice measure was the primary factor predicting trust and confidence in police, followed by perceptions that the police effectively deal with crime in the community. Having said that, however, the particularly important finding from this regression analysis is that the experimental manipulation continued to significantly, and positively, effect trust and confidence even after these general views were considered. So even when general views are taken into account, actually receiving procedural justice during a short police-initiated contact has the ability to positively shape trust and confidence in police. This finding is consistent with results from Mazerolle et al (2013).

We also note that demographic background variables played little role in predicting differences in trust and confidence across the two groups. The results suggest that it is not demographics driving the differences in attitudes towards police in our trial, but rather the experimental manipulation itself. Our findings reveal that gender was the only demographic 
variable that predicted differences in trust and confidence in police, with women being more trusting than men. The general lack of demographic effects is important because it shows that in an experimental test of procedural justice policing, personal experiences appear to matter more than demographic factors.

[insert Table 3 about here]

In addition to examining the effects of the experimental manipulation on public trust and confidence in police, we also examined whether receiving procedural justice during a policeinitiated encounter could influence drivers' feelings of obligation to obey police, and their willingness to cooperate with police in collaborative crime control efforts. Two additional regression analyses were undertaken, in which the experimental manipulation variable was entered into the regression model, in conjunction with a set of attitudinal and demographic control variables (see Table 4).

[insert Table 4 about here]

While the experimental manipulation variable had a direct positive effect on drivers' trust and confidence in police, results presented in Table 4 show that the experimental manipulation did not have a significant effect on drivers' obligation to obey police (Model 1). Nor did it have a direct effect on their willingness to cooperate with police (Model 2). Having said that, Table 4 does show that trust and confidence in police was a significant predictor of both obligation to obey police and willingness to cooperate with police. With the experimental manipulation being found to have a positive and significant impact on trust and confidence in police, such a finding suggests that police may still reap the benefits of increased deference and cooperation if they can effectively build public trust and confidence in police.

It can also be seen in Model 1 that gender predicted obligation to obey police. We found that women were more likely than men to feel greater obligation to obey police. Model 2 demonstrates that both gender and age significantly predicted willingness to cooperate with police, suggesting that older people and women are most likely to cooperate with police. But again, these findings are relatively weak. Instead, general perceptions of procedural justice, perceptions about police effectiveness, and trust and confidence in police mattered most to people when determining whether they would obey police or cooperate with them. 
Other noteworthy findings from these two additional regression analyses include that the relationship between police effectiveness and the obligation to obey police was relatively weak; more important factors were general perceptions of police use of procedural justice, and trust and confidence in police. In contrast, police effectiveness appeared to matter a great deal for predicting citizens' willingness to cooperate with police in collaborative crime control efforts. Police effectiveness appeared to be the key factor in determining who would and would not cooperate with police. The general procedural justice measure was a relatively weak predictor of cooperation, which contradicts many previous findings from the procedural justice literature. 'Trust and confidence' was also a fairly weak predictor of cooperation, although it mattered more to citizens than did general views about police use of procedural justice. These findings are interesting because prior Australian research (see Hinds and Murphy 2007; Sargeant, Murphy and Cherney under review) has revealed that Australians appear to place greater weight on instrumental factors than American populations (see also Tankebe's 2009 study in an African context). One final comment on the results relates to the model fit statistics. For both 'trust' and 'obligation to obey', the $\mathrm{R}^{2}$ values exceeded .30 . However, the $\mathrm{R}^{2}$ value for the 'cooperation' model was only .15. While somewhat low, it should be noted that this value is not substantially lower than many model fit values reported in the procedural justice literature, particularly for those studies that have undertaken factor analytic techniques to ensure their variables of interest are conceptually distinct.

\section{Discussion}

A great deal of scholarship now exists which demonstrates that people value procedurally just encounters with authorities. This scholarship shows that procedural justice yields a number of positive benefits for police, including increased trust and confidence in police, increased deference to police requests, increased compliance with the law more generally, and increased willingness to cooperate with police in collaborative crime control efforts (eg. Sunshine and Tyler 2003; Murphy et al. 2008; Reisig, Bratton and Gertz 2007; Tyler and Huo 2002; Tyler 1990). This past research has been limited, however, in that findings have been based primarily on correlational or observational data. The present study aimed to test whether procedural justice-based policing could work in practice. It did so by examining the results from the first randomized experimental field trial of procedural justice policing. 
In summary, it was found that the procedural justice manipulation yielded a significant effect on public trust and confidence in police. Specifically, citizens who were exposed to the procedural justice condition during the RBT encounter were significantly more likely to trust police than those who received the control protocol. This effect remained even after accounting for general perceptions about police treatment of citizens and perceptions of police effectiveness. This finding is significant because it supports correlational results from prior procedural justice research (e.g., Tyler and Huo 2002). But more importantly, this is the first time in the literature that such a result has been demonstrated using a randomized experimental field trial.

What our paper shows, however, is that the procedural justice manipulation (experimental treatment) did not have a positive effect on drivers' general feelings of obligation to obey police or their willingness to cooperate with police. Those who received the procedural justice protocol during the RBT encounter were no more likely to indicate that they would feel an obligation to obey police than were those exposed to the control condition. Similarly, those in the procedural justice condition were not more likely to indicate they would cooperate with police than those in the control condition.

We suggest that the unique nature of RBT encounters might explain this finding. It may be that the routineness of RBT testing in Australia may dilute any beneficial effects of procedural justice on peoples' willingness to cooperate with police. Random breath testing in Australia is a common form of contact between citizens and police and is widely accepted by the public as a deterrence strategy for reducing drunk driving. Hence, it would be fair to say that such an encounter is fairly benign in nature. It is perhaps not surprising, then, that the manipulation did not produce significant effects on these variables. In observational research of police-citizen encounters, McCluskey (2003) found that escalation of conflict was less likely to arise in encounters that utilised procedural justice. In encounters where police were more verbally aggressive or disrespectful of citizens, defiance and escalation of violence was more common. Similarly, Paternoster et al. (1997) found that domestic violence offenders who were arrested by police were less likely to recidivate if they felt their encounter with police had been procedurally fair. Those who felt the experience was procedurally unfair were more likely to commit the offence again. Perhaps in more extreme situations (e.g. when implementing an arrest; trying to break up a fight etcetera), a procedural justice manipulation 
may have an effect on obligation to obey or willingness to cooperate with police. Future studies may wish to examine this.

While highlighting the limitation of the context in which the experimental manipulation was conducted, we do not want to detract from the main finding of this study; that trust and confidence in police can be enhanced through a single short encounter with police. Contrary to the findings of Skogan (2006) — who found that positive encounters with police mattered little for shaping positive perceptions of police while negative encounters had significant negative effects on perceptions of police-our results show that fair treatment by police in only one, short encounter can have a significant positive impact on recipients' trust and confidence in police. Such a result supports the findings of Bradford et al.'s (2009) study. Using self-report survey data collected in the United Kingdom, Bradford et al. (2009) found that negative contact with police does reduce public opinion of police. However, they also found that positively received contacts could significantly influence positive perceptions of police. Given the experimental methodology used in our study, our findings provide a stronger and more reliable test of the positive effects of fair treatment. Our results also suggest that a personal encounter with police can have a positive effect on people's trust in police even when general perceptions about the police are taken into account. Brandl et al. (1994) found that personal experiences had little impact when taking general perceptions into account. Our results also contradict this finding.

Added to this, if we are to believe the vast majority of procedural justice studies that have been published to date, our results auger well for police agencies hoping to build community support for their actions. Prior research has shown that people should be more willing to cooperate with police and comply with the law if they have more trust and confidence in police (Tyler and Huo 2002). In our study we found that trust and confidence in police was related to feelings of obligation to obey and willingness to cooperate with police (see Table 4). The implication of these findings is that if members of the public have repeated positive experiences with police, then over time their feelings of obligation to obey police or their willingness to cooperate or comply with police can be enhanced through the effects of increased trust and confidence (trust has been shown to be directly shaped by personal encounters with police). 
Procedural justice has broad appeal for police agencies around the world. As noted in our Introduction, police agencies in the United States, the United Kingdom, and Australia have moved toward utilising procedural justice in encounters with the public. Training of new police recruits on the value of using procedural justice in encounters with the public has also occurred (Schuck and Rosenbaum 2011). Procedural justice has such appeal because it represents a tool that is both easy to implement and which has been shown to positively shape public perceptions of police. It is also much simpler for police to change the way in which they interact with members of the community than it is to change the level of crime in the community. The results of our study are particularly important because they show experimentally that procedural justice in practice is important for building public trust and confidence in police.

It should be noted at this stage, however, that any use of procedural justice by police should be meaningful. Greenberg (1990; see also Murphy and Cherney 2011) noted that authorities sometimes try to develop the appearance that they are procedurally fair as an impression management strategy. He notes that such a strategy may possibly have positive consequences in the short term but may eventually lead to a negative reputation of not being trustworthy in the long-term. Hence, any strategy that is adopted by police needs to convey a commitment to the principles of procedural fairness and needs to do so consistently over time. Otherwise, if members of the public come to view a strategy as "an impression management tactic, then the procedural rule will not be seen as meaningful, and consequently, the positive effect of procedural fairness on people's reciprocal behavioural displays of cooperation will be nonexistent” (DeCremer and Tyler 2007: 640)

In conclusion, trust in the overall institution of policing builds over time and after receiving consistent positive personal or vicarious encounters with police. The results of the present study demonstrate that one personal and positive encounter with police during a routine traffic stop can result in higher levels of trust and confidence in police. Contrary to the conclusions drawn by Brandl et al. (1994) and by Skogan (2006), we can conclude from our experimental study that police officers can build trust and confidence effectively if they utilise procedural justice during personal encounters with the public. 


\section{Footnotes}

1. In the course of a Random Breath Testing (RBT) encounter, police officers usually stand by the side of the road and signal to drivers to pull over. Selection for an RBT stop is done on a random basis. The driver is then instructed to provide a specimen of their breath by blowing into a calibrated breath-testing device. Within 20 seconds the results of the test are available to police. If the reading indicates that the amount of alcohol present in the person's system does not exceed 0.05 grams of alcohol per 100 millilitres of blood they are free to continue on their journey. If the driver records a positive reading $(>0.05)$, however, they are instructed to exit the vehicle and accompany police to a breath analysis station where a more thorough test is conducted. If drivers record a negative reading the encounter is necessarily very systematic and often devoid of anything but compulsory communication.

2. Lower scores on the educational attainment measure indicate higher levels of education. 


\section{References}

BEAN, C. (2004), 'Is there a Crisis of Trust in Australia?’ In S. Wilson et al, eds., Australian Social Attitudes: The $1^{\text {st }}$ Report, 122--140. Sydney: UNSW Press.

BRADFORD, B., JACKSON, J. and STANKO, E. (2009), 'Contact and Confidence: Revisiting the Impact of Public Encounters with the Police. Policing and Society, 19: 20-46.

BRANDLE, S., FRANK, J., WORDEN, R. and BYNUM, T. (1994), 'Global and Specific Attitudes Toward the Police: Disentangling the Relationship', Justice Quarterly, 11: 119-134.

CHAN, J. (1997), Changing police culture. Sydney: Federation Press.

CHERNEY, A. and CHUI, W. (2009), 'Policing Ethnically and Culturally Diverse Communities’. In A. Mulvane, ed., Policing in Context. South Melbourne: Oxford University Press.

COMMONWEALTH OF AUSTRALIA. (2010), National Youth Policing Model. Canberra: Attorney General's Department.

CORREIA, M. (2000), 'The Conceptual Ambiguity of Community in Community Policing', Policing: An International Journal of Police Strategies and Management, 23: 218--232.

DECREMER, D. and TYLER, T.R. (2007), 'The Effects of Trust in Authority and Procedural Fairness on Cooperation', Journal of Applied Psychology, 92: 639--649.

FOLGER, R. and KONOVSKY, M. (1989), 'Effects of Procedural and Distributive Justice on Reactions to Pay Raise Decisions', Academy of Management Journal, 32: 115--130.

GALLAGHER, C., MAGUIRE E., MASTROFSKI, S. \& REISIG, M. (2001), The Public Image of Police: Final report to the International Association of Chiefs of Police, available online at: http://www.theiacp.org/profassist/ethics/public_image.htm.

GALLUP. (2010), Confidence in Institutions, available from: http://www.gallup.com/poll/1597/confidence-institutions.aspx.

GOLDSMITH, A. (2005). 'Police Reform and the Problem of Trust', Theoretical Criminology, 9: 443--470.

GREENBERG, J. (1990), 'Looking Fair versus Being Fair: Managing Impressions of Organizational Justice', Research in Organizational Behavior, 12: 111--157.

HARDIN, R. (2006). Trust. Cambridge: Polity Press. 
HINDS, L. and MURPHY, K. (2007). Public Satisfaction with Police: Using Procedural Justice to Improve Police Legitimacy. The Australian and New Zealand Journal of Criminology, 40: 27--42.

HOHL, K., BRADFORD, B. and STANKO, E. (2010), 'Influencing Trust and Confidence in the London Metropolitan Police’, British Journal of Criminology, 50: 491--513.

HOUGH, M., JACKSON, J., BRADFORD, B., MYHILL, A. and QUINTON, P. (2010), 'Procedural Justice, Trust, and Institutional Legitimacy’, Policing, 4: 203--210.

JACKSON, J. and BRADFORD, B. (2009), 'Crime, Policing and Social Order: On the Expressive Nature of Public Confidence in Policing', The British Journal of Sociology, 60: 493--521.

JONATHAN-ZAMIR, T. and WEISBURD, D. (in press), 'The Effects of Security Threats on Antecedents of Police Legitimacy: Findings from a Quasi-experiment in Israel', Journal of Research in Crime and Delinquency.

KIM, W. and MAUBORGNE, R. (1993), 'Procedural Justice, Attitudes and Subsidiary Top Management Compliance with Multinationals' Corporate Strategic Decisions. Academy of Management Journal, 36: 502--526.

LEVI, M. (1998), 'A State of Trust', in V. Braithwaite \& M. Levi, eds., Trust and Governance, 77-101. New York: Sage.

MAZEROLLE, L., BENNETT, S., MANNING, M., FERGUSON, P. and SARGEANT, E. (2010). Legitimacy and Policing. Campbell Collaboration: Campbell Systematic Reviews.

MAZEROLLE, L., BENNETT, S., ANTROBUS, E., and EGGINS, E. (2012). Procedural justice, routine encounters and citizen perceptions of police: Main findings from the Queensland Community Engagement Trial (QCET). Journal of Experimental Criminology, 8: 343-367.

MAZEROLLE, L., ANTROBUS, E., BENNETT, S. and TYLER, T.R. (2013). Shaping citizen perceptions of police legitimacy: A randomized field trial of procedural justice. Criminology, 51: 33-63.

MCCLUSKEY, J. (2003). Police Requests for Compliance: Coercive and Procedurally Just Tactics. New York: LFB Scholarly Publications.

MURPHY, K. (2004). 'The Role of Trust in Nurturing Compliance: A Study of Accused Tax Avoiders', Law and Human Behavior, 28: 187-209.

MURPHY, K. (2009). 'Public Satisfaction with Police: The Importance of Procedural Justice and Police Performance in Police-citizen Encounters', The Australian and New Zealand Journal of Criminology, 42: 159-178. 
MURPHY, K. and BYNG, K. (2002). A User's guide to the Australian tax system survey of tax scheme investors. Centre for Tax System Integrity Working Paper No 39. Canberra: The Australian National University.

MURPHY, K. and CHERNEY, A. (2011), 'Fostering Cooperation with the Police: How Do Ethnic Minorities in Australia Respond to Procedural Justice-based Policing', The Australian and New Zealand Journal of Criminology, 44: 235--257.

MURPHY, K., HINDS, L., and FLEMING, J. (2008), 'Encouraging Public Cooperation and Support for Police', Policing and Society, 18: 138--157.

MURPHY, K. MURPHY, B. and MEARNS, M. (2010), 'The 2009 Public Safety and Security in Australia Survey: Survey Methodology and Preliminary Findings', Alfred Deakin Research Institute Working Paper No 17. Geelong: Deakin University.

PAERNOSTER, R., BRAME, R., BACHMAN, R., and SHERMAN, L.W. (1997), 'Do Fair Procedures Matter? The Effect of Procedural Justice on Spouse Assault', Law and Society Review, 31: 163--204.

REISIG, M., BRATTON, J. and GERTZ, M. (2007), 'The Construct Validity and Refinement of Process-based Policing Measures’, Criminal Justice and Behavior, 34: 1005--1028.

ROBERTS, L. and INDERMAUR, D. (2009), 'What Australians Think about Crime and Justice: Results from the 2007 Australian Survey of Social Attitudes', Australian Institute of Criminology Research and Public Policy Series 101. Canberra: Australian Institute of Criminology.

ROSENBAUM, D. and LAWRENCE D. (2012), 'Teaching Respectful Police-citizen Encounters and Good Decision-making: Results of a Randomized Control Trial with Police Recruits', National Police Research Platform Report. Washington: National Institute of Justice.

SAMPSON, R. and JEGLUM-BARTUSCH, D. (1998), 'Legal cynicism (and Subcultural?) Tolerance of Deviance: The Neighbourhood Context of Racial Differences', Law and Society Review, 32: 777--804.

SARGEANT, E., MURPHY, K. and CHERNEY, A. (under review), 'Ethnicity, Trust and Cooperation with Police: Testing the Dominance of the Process-based Model. Brisbane: Griffith University.

SCHOLZ, J. and LUBELL, M. (1998), 'Trust and Taxpaying: Testing the Heuristic Approach to Collective Action', American Journal of Political Science, 42: 398--417. 
SCHUCK, A. and ROSENBAUM, D. (2011), 'The Chicago Quality Interaction Training Program: A Randomized Control Trial of Police Innovation', National Police Research Platform Topical Report. Washington: National Institute of Justice.

SKOGAN, W. (2006), 'Asymmetry in the Impact of Encounters with Police', Policing and Society, 16: 99--126.

SKOGAN, W. and FRYDL, K. (2004), Fairness and Effectiveness in Policing. Washington: National Academy Press.

SKOGAN, W. and STEINER, L. (2004), Community Policing in Chicago: Year 10. Chicago: Criminal Justice Information Authority.

SUNSHINE, J. and TYLER, T.R. (2003), 'The Role of Procedural Justice and Legitimacy in Shaping Public Support for Policing’, Law and Society Review, 37: 513--547.

TANKEBE, J. (2009), 'Public Cooperation with the Police in Ghana: Does Procedural Fairness Matter?’, Criminology, 47: 1265--1293.

TYLER, T.R. (1990), 'Why People Obey the Law’. New Haven: Yale University Press.

TYLER, T.R. (2004), 'Enhancing Police Legitimacy’, Annals of the American Academy, 593: 84--99.

TYLER, T.R. (2006), Why people obey the law. Princeton: Princeton University Press.

TYLER, T.R. (2005), 'Policing in Black and White: Ethnic Group Differences in Trust and Confidence in the Police', Police Quarterly, 8: 322--342.

TYLER, T.R. and DEGOEY, P. (1996), 'Trust in Organizational Authorities: The Influence of Motive Attributions on Willingness to Accept Decisions’, In R. Kramer and T.R. Tyler, eds., Trust in organizations: Frontiers of Theory and Research, 331-356. London: Sage.

TYLER, T.R. and HUO, Y. (2002), Trust in the Llaw. New York: Russell Sage Foundation.

TYLER, T.R. and MURPHY, K. (2011), 'Procedural Justice, Police Legitimacy and Cooperation with the Police: A New Paradigm for Policing', Australian Research Council Centre of Excellence in Policing and Security Briefing Paper. Brisbane: Griffith University.

WHELlER, L., MILLS, A. and QUINTON, P. (2012). The Greater Manchester Police Procedural Justice Training Experiment. Paper presented at the $5^{\text {th }}$ International Conference on Evidence Based Policing, Cambridge, United Kingdom, 9-11 July 2012. 


\section{Appendix}

Below is a complete list of measures used in this paper.

\section{Specific procedural justice}

During this last RBT encounter........

- The police officer treated me with dignity and respect

- The police officer was polite when dealing with me

- The police officer was fair when making the decision to stop me

- The police officer gave me the opportunity to express my views

- The police officer listened to me during the RBT

\section{General procedural justice}

- Police try to be fair when making decisions

- Police give people the opportunity to express their views before decisions are made

- Police listen to people before making decisions

- Police treat people with dignity and respect

- Police are always polite when dealing with people

\section{Police effectiveness}

On the whole, how good a job do you think the police are doing in your neighbourhood at...

- Solving crime

- Dealing with problems that concern you

- Working with your community to solve local problems

- Preventing crime

\section{Trust and confidence}

During this last RBT encounter.....

- I felt that the police officer was trustworthy

- I had confidence that the police officer was doing the right thing

- I was satisfied with the way the police officer conducted the RBT

- I was satisfied with how I was treated 


\section{Obligation to obey police}

- I feel a moral obligation to obey the law

- I feel a moral obligation to obey police

- Overall, I obey police with good will

\section{Willingness to cooperate with police}

How likely would you be to...

- Call police to report a crime

- Help police to find someone suspected of committing a crime by providing them with information

- Report dangerous or suspicious activities to police

- Willingly assist police if asked 
Table 1. Principal components analysis, using oblimin rotation differentiating items used to construct the scales used in this paper.

\begin{tabular}{|c|c|c|c|c|c|}
\hline \multirow[t]{2}{*}{ Item } & \multicolumn{5}{|c|}{ Factor } \\
\hline & 1 & 2 & 3 & 4 & 5 \\
\hline \multicolumn{6}{|l|}{ Procedural justice-general } \\
\hline Police listen to people & .94 & & & & \\
\hline Police give opportunity to express views & .92 & & & & \\
\hline Police are always polite & .79 & & & & \\
\hline Police treat people with dignity/respect & .76 & & & & \\
\hline Police try to be fair & .58 & & & & \\
\hline \multicolumn{6}{|l|}{ Police effectiveness } \\
\hline Working with community & & -.92 & & & \\
\hline Preventing crime & & -.91 & & & \\
\hline Dealing with problems that concern you & & -.91 & & & \\
\hline Solving crime & & -.89 & & & \\
\hline \multicolumn{6}{|l|}{ Cooperation } \\
\hline Call police to report crime & & & .82 & & \\
\hline Help police find suspect & & & .80 & & \\
\hline Report dangerous/suspicious activity & & & .70 & & \\
\hline Willing assist police if asked & & & .52 & & \\
\hline \multicolumn{6}{|l|}{ Trust and confidence } \\
\hline Was satisfied with officer conduct in RBT & & & & .95 & \\
\hline I had confidence the officer was doing right & & & & .88 & \\
\hline I was satisfied with how I was treated & & & & .84 & \\
\hline I felt the officer was trustworthy & & & & .79 & \\
\hline \multicolumn{6}{|l|}{ Obligation to obey } \\
\hline I feel a moral obligation to obey the law & & & & & -.94 \\
\hline I feel a moral obligation to obey police & & & & & -.84 \\
\hline Overall, I obey police with good will & & & & & -.81 \\
\hline Eigenvalues & 8.65 & 1.78 & 1.73 & 1.37 & 1.20 \\
\hline Explained variance (\%) & 43.26 & 8.90 & 8.66 & 6.86 & 5.97 \\
\hline
\end{tabular}


Table 2. Means and standard deviations across the experimental and control conditions. (standard deviations in brackets)

\begin{tabular}{lll}
\hline & & Condition \\
Measures & Experimental & Control \\
\hline Specific procedural justice & $4.22(.71)$ & $3.94(.72)^{* *}$ \\
General procedural justice & $3.59(.80)$ & $3.49(.78)^{*}$ \\
Police effectiveness & $3.55(.80)$ & $3.51(.78)$ \\
Trust and confidence & $4.35(.67)$ & $4.22(.65)^{* *}$ \\
Obligation to obey & $4.43(.60)$ & $4.42(.59)$ \\
Cooperation & $4.51(.62)$ & $4.52(.86)$ \\
\hline
\end{tabular}

Note: all scales measured on a 1 to 5 scale; t-tests reveal a significant difference across experimental and control conditions at ${ }^{*} \mathrm{p}<0.01$ and ${ }^{* *} \mathrm{p}<0.001$. 
Table 3 - OLS Regression predicting 'trust and confidence' in police

\begin{tabular}{llll}
\hline Predictor & $\underline{\mathrm{B}}$ & $\underline{\mathrm{SE}_{\mathrm{B}}}$ & $\underline{\beta}$ \\
\hline (Constant) & & & \\
Manipulation $(0=$ control $)$ & 2.18 & .08 & $.07 * *$ \\
Age & .10 & .02 & .07 \\
Gender $(0=$ male $)$ & .00 & .00 & -.01 \\
Education & .08 & .02 & $.06^{* *}$ \\
English speaking $(0=\mathrm{yes})$ & .00 & .01 & .01 \\
Gen. procedural justice & -.03 & .03 & -.02 \\
Police effectiveness & .41 & .02 & $.44^{* *}$ \\
\hline & .15 & .02 & $.18^{* *}$ \\
$\mathrm{R}^{2}$ & & & \\
Adjusted $\mathrm{R}^{2}$ & .34 & & \\
$\mathrm{~F}$ & .34 & & \\
$\mathrm{df}$ & $185.61^{* *}$ & & \\
& 7,2487 & & \\
\hline$* * \mathrm{p}<0.001$ & & &
\end{tabular}


Table 4. OLS Regression analyses showing predictors of 'obligation to obey police' (Model 1) and 'cooperation with police' (Model 2).

\begin{tabular}{|c|c|c|c|c|c|c|}
\hline & (Model 1: ol & gation & obey) & (Mod & соор & \\
\hline Predictor & $\underline{B}$ & $\underline{S E_{B}}$ & $\underline{\beta}$ & $\underline{\mathrm{B}}$ & $\underline{S E_{B}}$ & $\beta$ \\
\hline (Constant) & 2.12 & .08 & & 2.50 & .12 & \\
\hline Manipulation $(0=$ control $)$ & -.03 & .02 & -.03 & -.04 & .03 & -.03 \\
\hline Age & .00 & .00 & .02 & .00 & .00 & $.08^{* *}$ \\
\hline Gender ( $0=$ male $)$ & .13 & .02 & $.11^{* *}$ & .07 & .03 & $.04 *$ \\
\hline Education & .00 & .01 & .01 & .01 & .01 & .01 \\
\hline English speaking (0=yes) & .04 & .03 & .02 & -.06 & .04 & -.03 \\
\hline Gen. procedural justice & 26 & .02 & $.31 * *$ & .12 & .03 & $.11^{* *}$ \\
\hline Police effectiveness & .08 & .02 & $.11^{* *}$ & .20 & .02 & $.20 * *$ \\
\hline Trust and confidence & .21 & .02 & $.23 * *$ & .14 & .03 & $.12 * *$ \\
\hline $\mathrm{R}^{2}$ & .33 & & & .15 & & \\
\hline Adjusted $\mathrm{R}^{2}$ & .32 & & & .15 & & \\
\hline $\mathrm{F}$ & $149.50 * *$ & & & $54.38^{* *}$ & & \\
\hline df & 8,2469 & & & 8,2484 & & \\
\hline
\end{tabular}

${ }^{*} \mathrm{p}<0.05 ;{ }^{* *} \mathrm{p}<0.001$ 